\title{
Inhibitory and Stimulatory Effects of Selective Serotonin Reuptake Inhibitors on Cytochrome P450 2D6-mediated Dopamine Formation from p-Tyramine
}

\author{
Toshiro Niwa, Shizuya Sugimoto \\ School of Pharmacy, Shujitsu University, 1-6-1 Nishigawara, Naka-ku, Okayama 703-8516, Japan
}

Received, July 7, 2019; Revised, August 21, 2019; Accepted, October 25, 2019; Published, Nov 3, 2019.

\begin{abstract}
PURPOSE: The effects of selective serotonin reuptake inhibitors (SSRIs) such as fluoxetine and paroxetine on dopamine formation from $p$-tyramine, mediated by cytochrome P450 (CYP) 2D6.2 (Arg296Cys, Ser486Thr) and CYP2D6.10 (Pro34Ser, Ser486Thr), were compared with their effects on CYP2D6.1 (wild type)-mediated dopamine formation, to investigate the influence of a CYP2D6 polymorphism on neuroactive amine metabolism in the brain. METHODS: The Michaelis constants $\left(K_{\mathrm{m}}\right)$ and maximal velocity $\left(V_{\max }\right)$ values of dopamine formation mediated by CYP2D6.1, CYP2D6.2, and CYP2D6.10 (expressed in recombinant Escherichia coli), and inhibition constants $\left(K_{\mathrm{i}}\right)$ of the SSRIs toward dopamine formation catalyzed by the CYP2D6 variants were estimated. RESULTS: The $K_{\mathrm{m}}$ values for CYP2D6.2 and CYP2D6.10 decreased at lower fluoxetine concentrations, while the $V_{\max }$ values for all CYP2D6 variants increased, indicating that fluoxetine stimulated dopamine formation. Conversely, paroxetine competitively inhibited dopamine formation mediated by CYP2D6.1, CYP2D6.2, and CYP2D6.10 with $K_{\mathrm{i}}$ values of 0.47 , 1.33 , and $31.3 \mu \mathrm{M}$, respectively. CONCLUSIONS: These results suggest that the inhibition/stimulation of CYP2D6-mediated dopamine formation by these SSRIs would be affected by CYP2D6 polymorphisms in the brain.
\end{abstract}

\section{INTRODUCTION}

Cytochrome P450s (P450s or CYPs) catalyze the oxidation of endogenous compounds, including steroid hormones and neuroactive amines, as well as a wide variety of exogenous drugs $(1,2)$. CYP2D6 accounts for only $2-9 \%$ of all $\mathrm{P} 450$ s present in human livers $(3,4)$, but metabolizes approximately $20 \%$ of all therapeutic agents $(5,6)$. It is also expressed in the brain (midbrain) (7), howbeit with unknown physiological and pharmacological functions, specifically in the human brain.

CYP2D6 is expressed polymorphically; till date, 137 allelic variants and a series of subvariants of the CYP2D6 gene have been found, and this number continues to increase $(8,9)$. Interestingly, the CYP2D6 polymorphism has also been associated with human behavior $(10,11)$. For instance, poor metabolizers of CYP2D6 had a higher frequency of extreme responses compared with extensive metabolizers and scored significantly lower on the Karolinska Psychasthenia scale $(12,13)$. The CYP2D6*2 allele is present in $27-32 \%$ of Caucasian populations, and contains 2 amino acid substitutions; Arg296Cys and Ser486Thr (14). The Michaelis constants $\left(K_{\mathrm{m}}\right)$, maximal velocity $\left(V_{\max }\right)$, and $V_{\max } / K_{\mathrm{m}}$ values (intrinsic clearance, $C L_{\mathrm{int}}$ ) for $62-$
$85 \%$ of all CYP2D6.2-mediated metabolic reactions are comparable with those mediated by CYP2D6.1 (wild-type). However $K_{\mathrm{m}}$ values in $31 \%$ of CYP2D6.2-mediated reactions are more than 2-fold higher, and 15 and $38 \%$ of the $V_{\max }$ and $V_{\max } / K_{\mathrm{m}}$ values, respectively, are less than one-half (9). The $C Y P 2 D 6^{*} 10$ allele, including $C Y P 2 D 6^{*} 10 A$ and $C Y P 2 D 6^{*} 10 B$ variants, is widely observed in Japanese (31-38\%) $(13,14)$ and Chinese $(51 \%)(15)$ populations, and contains 2 amino acid substitutions; Pro34Ser and Ser486Thr (16,17). CYP2D6*36 (formerly CYP $2 D 6^{*} 10 C$ ) has a gene-conversion event at exon 9 derived from CYP2D7 and contains 13 more base substitutions than $C Y P 2 D 6^{*} 10 B(15)$. In CYP2D6.10-mediated metabolic reactions, 63\% of the $K_{\mathrm{m}}$ values are $>2$-folds higher, and 74 and $93 \%$ of the $V_{\max }$ and $V_{\max } / K_{\mathrm{m}}$ values, respectively, are less than $1 / 2(9)$.

Tyramine is exogenously present in fermented foods such as cheese and wine, and endogenously present in the brain, especially in the basal ganglia and limbic system (18).

Corresponding Author: Prof. Toshiro Niwa, Ph.D. School of Pharmacy, Shujitsu University, 1-6-1 Nishigawara, Naka-ku, Okayama 703-8516, Japan. E-mail: tniwa@shujitsu.ac.jp 
Dopamine, a neurotransmitter and precursor of noradrenaline and adrenaline, is formed from the biotransformation of $p$ - and $m$-tyramine, and dihydroxyphenylalanine (L-DOPA) in the brain, through CYP2D6-mediated ring-hydroxylation $(5,18-20)$. Initially, we demonstrated that quinidine (a typical human CYP2D6 inhibitor) and quinine (an inhibitor of rat CYP2D subfamily, including rat brain CYP2D4, rather than human CYP2D6) inhibited CYP2D6.10-mediated dopamine formation from $p$-tyramine to a lesser extent compared with those catalyzed by CYP2D6.1 and CYP2D6.2 (21).

We recently observed that imipramine and desipramine (a pharmacologically active $\mathrm{N}$ demethylated metabolite derived from imipramine by CYP1A2, CYP2C19, and CYP3A4), older generation tricyclic antidepressants (22-24), competitively or noncompetitively inhibited dopamine formation mediated by CYP2D6.1, CYP2D6.2, and CYP2D6.10, with higher inhibition constants $\left(K_{\mathrm{i}}\right)$ for CYP2D6.10 (25). Conversely, $V_{\max }$ values for dopamine formation by all CYP2D6 variants gradually increased with increasing concentrations of fluvoxamine, indicating that fluvoxamine stimulated dopamine formation (25). Fluvoxamine is a selective serotonin reuptake inhibitor (SSRI) widely used in the treatment of depression to overcome the toxicity of older generation antidepressants $(22,23,26-29)$. Recently many kinds of SSRIs, including the typical fluoxetine and paroxetine (Fig. 1), have been used (30). Thus, in this study, we investigated how CYP2D6 polymorphism affects the inhibitory/stimulatory effects of fluoxetine and paroxetine on CYP2D6-mediated formation of endogenous dopamine from $p$-tyramine in the brain.

\section{METHODS}

\section{Materials}

CYP2D6.1, CYP2D6.2, and CYP2D6.10 coexpressed with NADPH-P450 reductase were all expressed in recombinant Escherichia coli (Bactosomes), purchased from Cypex Ltd. (Dundee, UK). $\quad p$-Tyramine, dopamine, fluoxetine hydrochloride, and paroxetine maleate were obtained from Tokyo Chemical Industry (Tokyo, Japan). All other reagents and organic solvents used were of the highest purity commercially available.

Fluoxetine

Paroxetine
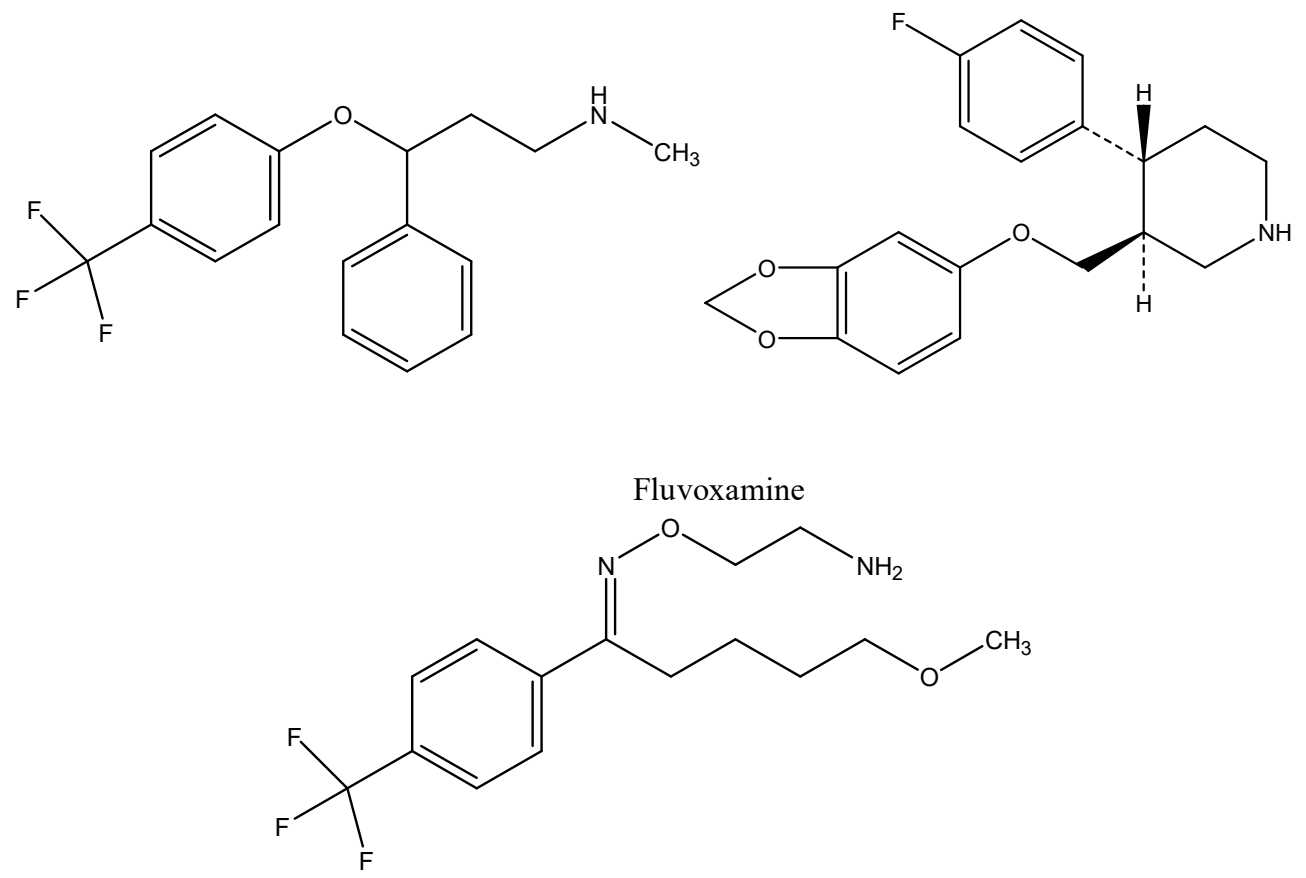

Figure. 1. Chemical structures of fluoxetine, paroxetine, and fluvoxamine. 


\section{Determination of dopamine formation}

Dopamine formation from $p$-tyramine in the presence or absence of SSRIs was determined as previously described (19,21,31). Briefly, the incubation mixture consisted of $10 \mathrm{nM}$ CYP2D6 variants, $0.05-10 \mathrm{mM}$-tyramine, $1 \mathrm{mM}$ NADPH, $50 \mu \mathrm{l}$ of water or $0.5-1000 \mu \mathrm{M}$ SSRIs dissolved in water, and $100 \mathrm{mM}$ potassium phosphate buffer $(\mathrm{pH}$ 7.4) in a final volume of $500 \mu \mathrm{l}$. After pre-incubation at $37^{\circ} \mathrm{C}$ for $3 \mathrm{~min}$, the reaction was activated by adding NADPH, and the mixture was incubated at $37^{\circ} \mathrm{C}$ for $10 \mathrm{~min}$. Dopamine concentrations in the mixtures were measured using high performance liquid chromatography (HPLC). Tosoh (Tokyo, Japan) TSK-gel ODS-120T (5 $\mu \mathrm{m}, 4.6 \times 250 \mathrm{~mm})$ analytical columns were used, and the fluorescence intensities were determined at an excitation wavelength of $280 \mathrm{~nm}$ and an emission wavelength of $340 \mathrm{~nm}(19,21,31)$. The linearity of the reaction with P450 concentrations and incubation times were confirmed for CYP2D6.1 and its variants in preliminary experiments. Unless stated otherwise, the inhibitory/stimulatory effects of SSRIs on CYP2D6.1- and CYP2D6.2-mediated dopamine formation were investigated at $0.1 \mathrm{mM}$ substrate concentration, and $1 \mathrm{mM}$ substrate concentration was used for CYP2D6.10-mediated reactions. These substrate concentrations were close to or $<K_{\mathrm{m}}$ values previously reported $(21,31)$.

\section{DATA ANALYSES}

All data were analyzed using the means of duplicate or triplicate reactions, and $K_{\mathrm{m}}, V_{\max }$, and $K_{\mathrm{i}}$ values and the standard deviations (S.D.) as indices of the precision of the calculated parameters were calculated from Michaelis-Menten kinetics using nonlinear least squares regression by means of MULTI (32). Statistical significance was determined by Student's $t$-test, and the significance level was set at $p<0.05$. JMP 5 software (SAS Institute Inc, Cary, $\mathrm{NC}$, USA) was used for the statistical analysis.

\section{RESULTS}

Firstly, we investigated the effect of fluoxetine and paroxetine at $0.1,0.1$, and $1 \mathrm{mM}$ substrate concentrations for CYP2D6.1, CYP2D6.2, and CYP2D6.10, respectively (Fig. 2). Fluoxetine at 1 $\mu \mathrm{M}$ stimulated dopamine formation catalyzed by CYP2D6.2 and CYP2D6.10, but not CYP2D6.1. Conversely, paroxetine at $1 \mu \mathrm{M}$ and $10 \mu \mathrm{M}$ inhibited CYP2D6.1- and CYP2D6.2-mediated dopamine formation by $49-68 \%$ and $74-89 \%$, respectively, while CYP2D6.10 was inhibited by $42 \%$, only at 100 $\mu \mathrm{M}$ (Fig. 2).

\section{Fluoxetine}

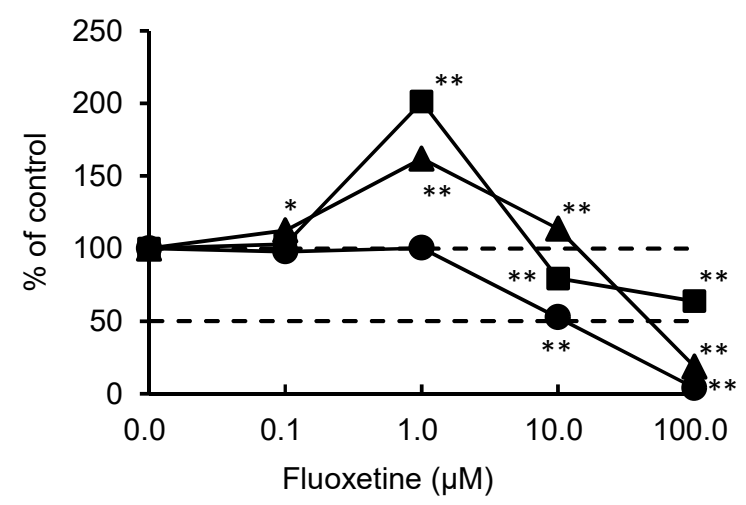

Paroxetine

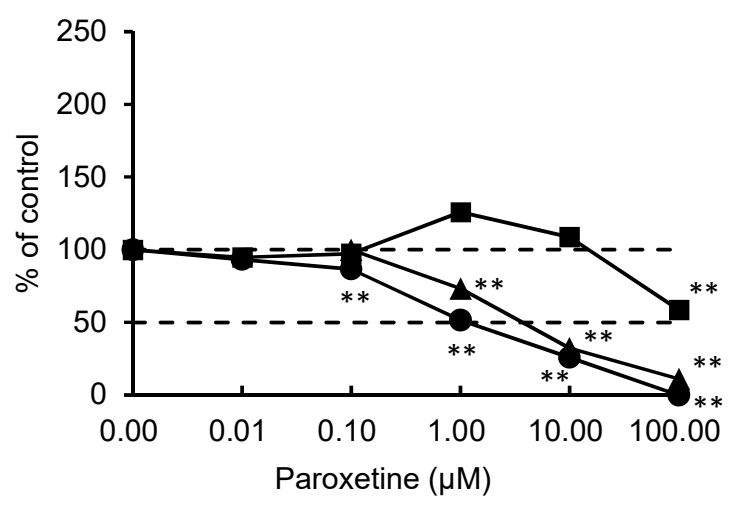

Fig. 2. Effects of fluoxetine and paroxetine on dopamine formation from $p$-tyramine mediated by CYP2D6.1, CYP2D6.2, and CYP2D6.10.

•: CYP2D6.1, $\boldsymbol{\Delta}$ : CYP2D6.2, $\mathbf{~ : ~ C Y P 2 D 6 . 1 0 . ~ S u b s t r a t e ~ c o n c e n t r a t i o n s ~ f o r ~ C Y P 2 D 6 . 1 ~ a n d ~ C Y P 2 D 6 . 2 ~ w e r e ~ 0 . 1 ~ m M , ~}$ and $1 \mathrm{mM}$ substrate concentration was used for reactions mediated by CYP2D6.10. Values are means of duplicate or triplicate determinations. ${ }^{*} p<0.05$ and $* * p<0.01$ vs control. 
Dopamine formation mediated by CYP2D6 and its variants in the presence of various concentrations of fluoxetine was compared (Table 1). The $K_{\mathrm{m}}$ value for CYP2D6.1 increased with increasing fluoxetine, while $K_{m}$ values for CYP2D6.2 and CYP2D6.10 decreased at concentrations below 1 and $5 \mu \mathrm{M}$, respectively and then increased with increasing fluoxetine in CYP2D6.2. Although the $V_{\max }$ values for CYP2D6.1 and CYP2D6.2 gradually increased with increasing fluoxetine, the $V_{\max }$ value for CYP2D6.10 increased at only $5 \mu \mathrm{M}$. Thus, $V_{\max }$ and
$V_{\max } / K_{\mathrm{m}}$ values for all CYP2D6 variants except the $V_{\max } / K_{\mathrm{m}}$ value for CYP2D6.1, increased to a maximum of 1.4-1.8 times and 2.3-3.4 times, respectively.

Paroxetine competitively inhibited dopamine formation mediated by CYP2D6.1, CYP2D6.2, and CYP2D6.10 with $K_{\mathrm{i}}$ values of $0.47,1.33$, and 31.3 $\mu \mathrm{M}$, respectively (Fig. 3); the estimated $K_{\mathrm{i}}$ values of paroxetine against CYP2D6.2 and CYP2D6.10 were 3 and 67 times, higher than that against CYP2D6.1, respectively.

Table 1. Effect of fluoxetine on kinetic parameters of dopamine formation

\begin{tabular}{|c|c|c|c|c|c|c|c|}
\hline \multirow{2}{*}{$\frac{\text { CYP2D6 }}{\text { CYP2D6.1 }}$} & \multirow{2}{*}{$\begin{array}{c}\text { Fluoxetine } \\
(\mu \mathrm{M})\end{array}$} & \multicolumn{2}{|l|}{$\begin{array}{c}K_{\mathrm{m}} \\
(\mathrm{mM})\end{array}$} & \multicolumn{2}{|c|}{$\begin{array}{c}V_{\max } \\
(\mathrm{nmol} / \mathrm{min} / \mathrm{nmol} \mathrm{P} 450)\end{array}$} & \multicolumn{2}{|c|}{$\begin{array}{l}V_{\max } / K_{\mathrm{m}} \\
(\mu \mathrm{L} / \mathrm{min} / \mathrm{nmol} \mathrm{P} 450)\end{array}$} \\
\hline & & $0.14 \pm 0.02$ & $(100)$ & $7.1 \pm 0.3$ & $(100)$ & 50.2 & $(100)$ \\
\hline & 1 & $0.16 \pm 0.03$ & (114) & $9.8 \pm 0.6$ & (137) & 60.4 & $(120)$ \\
\hline & 4 & $0.35 \pm 0.02$ & $(245)$ & $13.4 \pm 0.3$ & (189) & 38.6 & ( 77) \\
\hline & 10 & $1.38 \pm 0.12$ & $(976)$ & $17.3 \pm 0.8$ & (244) & 12.5 & $(25)$ \\
\hline \multirow[t]{4}{*}{ CYP2D6.2 } & 0 & $0.17 \pm 0.02$ & $(100)$ & $7.2 \pm 0.3$ & $(100)$ & 41.9 & $(100)$ \\
\hline & 0.1 & $0.10 \pm 0.02$ & $(57)$ & $6.7 \pm 0.3$ & (92) & 68.1 & $(162)$ \\
\hline & 1 & $0.10 \pm 0.02$ & ( 59) & $9.6 \pm 0.6$ & (133) & 94.6 & $(225)$ \\
\hline & 10 & $0.29 \pm 0.06$ & $(165)$ & $13.1 \pm 0.9$ & $(180)$ & 45.8 & (109) \\
\hline \multirow[t]{4}{*}{ CYP2D6.10 } & 0 & $1.18 \pm 0.28$ & $(100)$ & $6.8 \pm 0.6$ & $(100)$ & 5.7 & (100) \\
\hline & 0.2 & $1.02 \pm 0.38$ & $(86)$ & $6.9 \pm 0.9$ & (102) & 6.8 & (119) \\
\hline & 1 & $0.41 \pm 0.09$ & (35) & $6.6 \pm 0.4$ & (98) & 16.1 & $(282)$ \\
\hline & 5 & $0.47 \pm 0.06$ & $(40)$ & $9.2 \pm 0.3$ & (135) & 19.6 & (342) \\
\hline
\end{tabular}

Values in parentheses show the percentage of control. Values are means \pm S.D. of the data set using a nonlinear kinetic analysis from mean values obtained in duplicate or triplicate at each substrate/inhibitor concentration.

\section{CYP2D6.1}

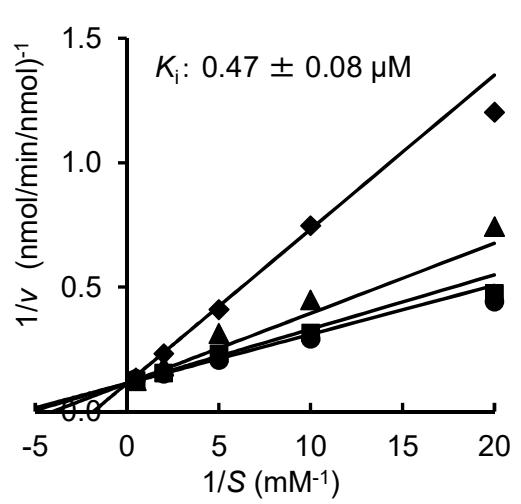

CYP2D6.2

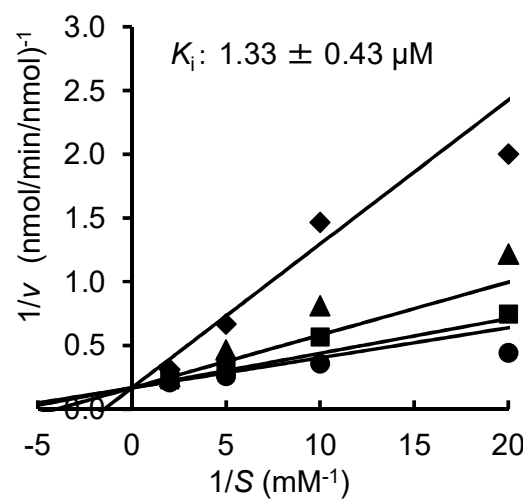

CYP2D6.10

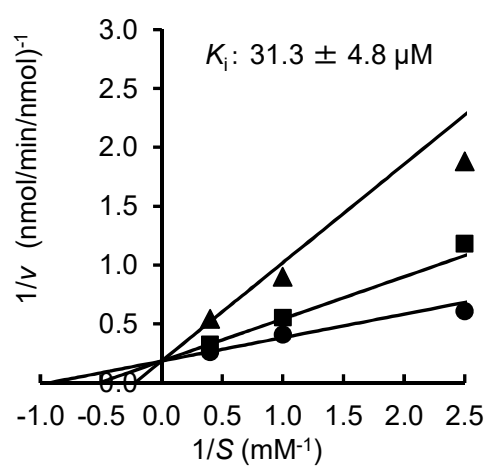

Figure. 3. Inhibitory effects of paroxetine on dopamine formation from $p$-tyramine mediated by CYP2D6.1, CYP2D6.2, and CYP2D6.10.

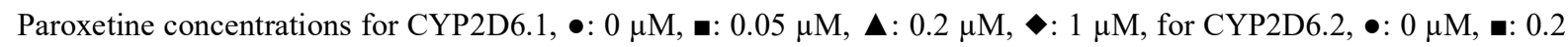
$\mu \mathrm{M}, \boldsymbol{\Delta}: 1 \mu \mathrm{M}, \diamond: 5 \mu \mathrm{M}$, for CYP2D6.10, $\bullet: 0 \mu \mathrm{M}, \mathbf{a}: 25 \mu \mathrm{M}, \boldsymbol{\Delta}: 100 \mu \mathrm{M} . K_{\mathrm{i}}$ values are means \pm S.D. of the data set using a nonlinear kinetic analysis from mean values obtained in duplicate or triplicate at each substrate/inhibitor concentration. 


\section{DISCUSSION}

Human CYP2D6 is expressed in the liver and brain, especially the midbrain (7). Previously we observed that dopamine formation from $p$-tyramine as well as progesterone hydroxylation were affected by CYP2D6 polymorphism $(21,31)$. In addition, many of the reported kinetic parameters such as $K_{\mathrm{m}}, V_{\max }$, and $V_{\max } / K_{\mathrm{m}}$, of CYP2D6.2 and CYP2D6.10 were different from those of CYP2D6.1 (wild type) (9). Unlike reports on metabolic activities, only a few reports exist on the inhibitory effects of CYP2D6 polymorphism on the inhibition of CYP2D6mediated reactions induced by exogenous compounds such as antidepressants. We recently observed that the $K_{\mathrm{i}}$ values of quinidine (a typical strong inhibitor of CYP2D6 in vitro, as recommended in the guidance for drug interaction studies by US FDA (33), EMA (34), and Japanese PMDA (35)) and quinine (a potent inhibitor of the rat CYP2D subfamily, including rat brain CYP2D4 (36-39)) against CYP2D6.1 were lower than those against CYP2D6.10. Furthermore, we previously demonstrated that psychotropic drugs such as imipramine, desipramine, fluoxetine, and mazindol, inhibited 21-hydroxylation of progesterone and/or allopregnanolone (a neuroactive steroid), mediated by CYP2D6 and CYP2D4. However, fluoxetine increased the $K_{\mathrm{m}}$ and $V_{\max }$ values of CYP2D6mediated progesterone 21-hydroxylation (40). Imipramine and desipramine inhibited dopamine formation from $p$-tyramine and the $K_{\mathrm{i}}$ values for CYP2D6.10 were higher than those for CYP2D6.1 (25). In this study, paroxetine inhibited dopamine formation with a higher $K_{\mathrm{i}}$ value for CYP2D6.10 compared with that for CYP2D6.1. These results suggested that the inhibition of CYP2D6 by various psychotropic drugs, including these antidepressants, would be affected by CYP2D6 polymorphism in the brain.

We have reported that steroid hormones such as progesterone and testosterone, stimulate the metabolism of CYP3A4 substrates; however, selection of the enzyme source (recombinant P450s or liver microsomes) can affect enzyme activation (41). More so, some researchers have demonstrated the activation of CYP3A4-mediated metabolic reactions, with no information on the detailed mechanism (40-42). This activation has similarly been demonstrated for other P450s such as CYP1A2, CYP2C8, CYP2C9, CYP2D6, and CYP3A7 (42). We previously observed that fluoxetine increased the $K_{\mathrm{m}}$ and $V_{\max }$ values for CYP2D6-mediated progesterone 21-hydroxylation (40), and that fluvoxamine and other SSRIs increased the $K_{\mathrm{m}}$ and $V_{\max }$ values for dopamine formation mediated by CYP2D6.1, CYP2D6.2, and CYP2D6.10, but decreased the $K_{\mathrm{m}}$ value for CYP2D6.10 to the level for CYP2D6.1 and CYP2D6.2 (25). Fluoxetineinduced activation of CYP2D6-mediated progesterone 21-hydroxylation was the first finding in relation to CYP2D6 $(40,42)$. In this study, fluoxetine also increased $K_{\mathrm{m}}$ and $V_{\max }$ values for dopamine formation mediated by CYP2D6.1 and its variants and decreased the $K_{\mathrm{m}}$ value for CYP2D6.10 to similar levels as those of CYP2D6.1 and CYP2D6.2. These results suggest that the CYP2D6 activation pattern would be affected by CYP2D6 polymorphism. Apart from selective inhibition of serotonin reuptake, some SSRIs such as fluoxetine and fluvoxamine that are metabolized by CYP2D6, exhibit novel physiological actions via the activation of dopamine formation and 21-hydroxylation of neurosteroids, including progesterone and allopregnanolone, mediated by brain CYP2D6 (43). Interestingly, fluoxetine and fluvoxamine but not paroxetine have a trifluoromethylphenoxy group in their chemical structure (Fig. 1), suggesting that this functional moiety may be essential for activation. On the other hand, not only paroxetine but also fluoxetine were demonstrated to inhibit CYP2D6catalyzed sparteine oxidation in human liver microsomes $(44,45)$, indicating that the activation/inhibition depends on the substrates. Further investigations like using three-dimensional structural analyses such as molecular docking simulation $(46,47)$, should be conducted to determine the underlying reason.

In conclusion, this study suggests that unlike paroxetine, fluoxetine stimulate CYP2D6-mediated dopamine formation from $p$-tyramine, and CYP2D6 polymorphism affect the inhibitory/stimulatory potency of SSRIs. However, further clinical studies are required to confirm the therapeutic relevance of our findings.

\section{ACKNOWLEDGEMENTS}

We would like to thank Editage (www.editage.com) for English language editing.

\section{REFERENCES}

1. Rendic S. Summary of information on human CYP enzymes: human P450 metabolism data. Drug Metab Rev, 2002;34:83-448. 
2. Niwa T, Murayama N, Imagawa $\mathrm{Y}$, Yamazaki H. Regioselective hydroxylation of steroid hormones by human cytochromes P450. Drug Metab Rev, 2015;47:89-110.

DOI: 10.3109/03602532.2015.1011658.

3. Shimada T, Yamazaki H, Mimura M, Inui $Y$, Guengerich FP. Interindividual variations in human liver cytochrome P-450 enzymes involved in the oxidation of drugs, carcinogens and toxic chemicals: studies with liver microsomes of 30 Japanese and 30 Caucasians. J Pharmacol Exp Ther, 1994;270:414-423.

4. Imaoka S, Yamada T, Hiroi T, Hayashi K, Sakaki T, Yabusaki Y, Funae Y. Multiple forms of human P450 expressed in Saccharomyces cerevisiae. Systematic characterization and comparison with those of the rat. Biochem Pharmacol, 1996;51:1041-1050.

5. Funae $Y$, Kishimoto W, Cho T, Niwa T, Hiroi T. CYP2D in the brain. Drug Metab Pharmacokinet, 2003; 18:337-349.

6. Williams JA, Hyland R, Jones BC, Smith DA, Hurst S, Goosen TC, Peterkin V, Koup JR, Ball SE. Drugdrug interactions for UDP-glucuronosyltransferase substrates: a pharmacokinetic explanation for typically observed low exposure (AUCi/AUC) ratios. Drug Metab Dispos, 2004;32:1201-1208.

7. McFayden MC, Melvin WT, Murray GI. Regional distribution of individual forms of cytochrome $\mathrm{P} 450$ mRNA in normal adult human brain. Biochem Pharmacol, 1998;55:825-830.

8. The Human Cytochrome P450 (CYP) Allele Nomenclature Committee. The Human Cytochrome P450 (CYP) Allele Nomenclature Database. 2017. Available at: https://www.pharmvar.org/gene/CYP2D6.

Accessed July 7, 2019.

9. Niwa T, Murayama N, Yamazaki H. Comparison of cytochrome P450 2D6 and variants in terms of drug oxidation rates and substrate inhibition. Curr Drug Metab, 2011;12:412-435.

10. Bertilsson L, Alm C, De Las Carreras C, Widen J, Edman G, Schalling D. Debrisoquine hydroxylation polymorphism and personality. Lancet, 1989;1(8637):555.

11. Llerena A, Edman G, Cobaleda J, Benítez J, Schalling D, Bertilsson L. Relationship between personality and debrisoquine hydroxylation capacity. Suggestion of an endogenous neuroactive substrate or product of the cytochrome P4502D6. Acta Psychiatr Scand, 1993;87:23-28.

12. $\mathrm{Yu}$ A, Kneller BM, Rettie AE, Haining RL. Expression, purification, biochemical characterization, and comparative function of human cytochrome P450 2D6.1, 2D6.2, 2D6.10, and 2D6.17 allelic isoforms. J Pharmacol Exp Ther, 2002;303:1291-1300.
13. Kubota T, Yamaura Y, Ohkawa N, Hara H, Chiba K. Frequencies of CYP2D6 mutant alleles in a normal Japanese population and metabolic activity of dextromethorphan $O$-demethylation in different CYP2D6 genotypes. $\mathrm{Br} \mathrm{J}$ Clin Pharmacol, 2000;50:31-34.

14. Nishida Y, Fukuda T, Yamamoto I, Azuma J. CYP2D6 genotypes in a Japanese population: low frequencies of CYP2D6 gene duplication but high frequency of CYP2D6*10. Pharmacogenetics, 2000;10:567-570.

15. Johansson I, Oscarson M, Yue QY, Bertilsson L, Sjöqvist F, Ingelman-Sundberg M. Genetic analysis of the Chinese cytochrome P4502D locus: characterization of variant CYP2D6 genes present in subjects with diminished capacity for debrisoquine hydroxylation. Mol Pharmacol, 1994;46:452-459.

16. Daly AK, Brockmöller J, Broly F, Eichelbaum M, Evans WE, Gonzalez FJ, Huang JD, Idle JR, Ingelman-Sundberg M, Ishizaki T, Jacqz-Aigrain E, Meyer UA, Nebert DW, Steen VM, Wolf CR, Zanger UM. Nomenclature for human CYP2D6 alleles. Pharmacogenetics, 1996;6:193-201.

17. Marez D, Legrand M, Sabbagh N, Lo Guidice JM, Spire C, Lafitte JJ, Meyer UA, Broly F. Polymorphism of the cytochrome P450 CYP2D6 gene in a European population: characterization of 48 mutations and 53 alleles, their frequencies and evolution. Pharmacogenetics, 1997; 7:193-202.

18. Philips SR, Rozdilsky B, Boulton AA. Evidence for the presence of $m$-tyramine, $p$-tyramine, tryptamine, and phenylethylamine in the rat brain and several areas of the human brain. Biol Psychiatry, 1978; 13:51-57.

19. Hiroi T, Imaoka S, Funae Y. Dopamine formation from tyramine by CYP2D6. Biochem Biophys Res Commun, 1998;249:838-843.

20. Haduch A, Bromek E, Daniel WA. Role of brain cytochrome P450 (CYP2D) in the metabolism of monoaminergic neurotransmitters. Pharmacol Rep, 2013;65:1519-1528.

21. Niwa T, Shizuku M, Yamano K. Effect of genetic polymorphism on the inhibition of dopamine formation from $p$-tyramine catalyzed by brain cytochrome P450 2D6. Arch Biochem Biophys, 2017;620:23-27. DOI: 10.1016/j.abb.2017.03.009.

22. Pacher P, Kecskemeti V. Cardiovascular side effects of new antidepressants and antipsychotics: new drugs, old concerns? Curr Pharm Des, 2004;10:2463-2475.

23. Deligiannidis KM, Byatt N, Freeman MP. Pharmacotherapy for mood disorders in pregnancy: a review of pharmacokinetic changes and clinical recommendations for therapeutic drug monitoring. J Clin Psychopharmacol, 2014;34:244-255. DOI: 10.1097/JCP.0000000000000087. 
24. Imidol interview form. Mitsubishi Tanabe Pharma. 2018, Available at: http://www.info.pmda.go.jp/go/pack/1174006F102 7_4_19/?view=frame\&style=SGML\&lang=ja. Accessed July 7. 2019.

25. Niwa T, Yanai M, Matsumoto M, Shizuku M. Effect of cytochrome P450 (CYP) 2D6 genetic polymorphism on the inhibitory action of antidepressants on CYP2D6-mediated dopamine formation from $p$-tyramine. J Pharm Pharm Sci, 2018;21:135-142. DOI: 10.18433/jpps29673.

26. Jakubovski E, Varigonda AL, Freemantle N, Taylor MJ, Bloch MH. Systematic review and metaanalysis: dose-response relationship of selective serotonin reuptake inhibitors in major depressive disorder. Am J Psychiatry, 2016;173:174-183. DOI: 10.1176/appi.ajp.2015.15030331.

27. Omori IM, Watanabe N, Nakagawa A, Cipriani A, Barbui C, McGuire H, Churchill R, Furukawa TA. Fluvoxamine versus other anti-depressive agents for depression. Cochrane Database Syst Rev, 2010;3 CD006114.

DOI: 10.1002/14651858.CD006114.pub2.

28. Luvox interview form. AbbVie Inc. 2019. Available at:

http://www.info.pmda.go.jp/go/pack/1179039F103 6_3_10/?view=frame\&style=SGML\&lang=ja. Accessed July 7, 2019.

29. Figgitt DP, McClellan KJ. Fluvoxamine. An updated review of its use in the management of adults with anxiety disorders. Drugs, 2000;60:925954.

30. Sharma T, Guski LS, Freund N, Gøtzsche PC. Suicidality and aggression during antidepressant treatment: systematic review and meta-analyses based on clinical study reports. BMJ, 2016;352:165. DOI: 10.1136/bmj.i65.

31. Niwa T, Hiroi $T$, Tsuzuki $D$, Yamamoto $S$, Narimatsu S, Fukuda T, Azuma J, Funae Y. Effect of genetic polymorphism on the metabolism of endogenous neuroactive substances, progesterone and $p$-tyramine, catalyzed by CYP2D6. Mol Brain Res, 2004;129:117-123.

32. Yamaoka K, Tanigawara Y, Nakagawa T, Uno T. A pharmacokinetic analysis program (multi) for microcomputer. J Pharmacobiodyn, 1981;4:879885.

33. U.S. Food and Drug Administration, Drug Development and Drug Interactions: Table of Substrates, Inhibitors and Inducers. 2017. Available at:

http://www.fda.gov/Drugs/DevelopmentApprovalP rocess/DevelopmentResources/DrugInteractionsLa beling/ucm093664.htm\#4. Accessed July 7, 2019.

34. European Medicines Agency, Guideline on the investigation of drug interactions. CPMP/EWP/560/95/Rev. 1 Corr. $2^{* *} .2012$.
Available

http://www.ema.europa.eu/docs/en GB/document library/Scientific_guideline/2012/07/WC50012960 6.pdf\#search $=$ 'European + Medicines + Agency $\% 2 \mathrm{C}$ + drug+interaction. Accessed July 7, 2019.

35. Pharmaceuticals and Medical Devices Agency, Methods of drug interaction studies (PMSB/ELD Notification No. 813; June 4, 2001). 2001. Available at:

http://www.nihs.go.jp/phar/pdf/DiGlEngFinal0112 09.pdf. Accessed July 7, 2019.

36. Hiroi $\mathrm{T}$, Imaoka $\mathrm{S}$, Chow $\mathrm{T}$, Funae $\mathrm{Y}$. Tissue distributions of CYP2D1, 2D2, 2D3 and 2D4 mRNA in rats detected by RT-PCR. Biochim Biophys Acta, 1998;1380:305-312.

37. Kishimoto W, Hiroi T, Shiraishi M, Osada M, Imaoka S, Kominami S, Igarashi $\mathrm{T}$, Funae $\mathrm{Y}$. Cytochrome P450 2D catalyze steroid 21hydroxylation in the brain. Endocrinology, 2004;145:699-705.

38. Komori M. A novel P450 expressed at the high level in rat brain, Biochem Biophys Res Commun, 1993;196:721-728.

39. Venhorst J, ter Laak AM, Commandeur JN, Funae Y, Hiroi T, Vermeulen NP. Homology modeling of rat and human cytochrome P450 2D (CYP2D) isoforms and computational rationalization of experimental ligand-binding specificities. J Med Chem, 2003;46:74-86.

40. Niwa $T$, Okada $K$, Hiroi $T$, Imaoka $S$, Narimatsu $S$, Funae Y. Effect of psychotropic drugs on the 21hydroxylation of neurosteroids, progesterone and allopregnanolone, catalyzed by rat CYP2D4 and human CYP2D6 in the brain. Biol Pharm Bull, 2008;31:348-351.

41. Niwa T, Shiraga T, Yamasaki S, Ishibashi K, Ohno $\mathrm{Y}$, Kagayama A. In vitro activation of 7benzyloxyresorufin $O$-debenzylation and nifedipine oxidation in human liver microsomes. Xenobiotica, 2003;33:717-729.

42. Niwa T, Murayama N, Yamazaki H. Heterotropic cooperativity in oxidation mediated by cytochrome P450. Curr Drug Metab, 2008;9:453-462.

43. Hiroi T, Kishimoto W, Chow T, Imaoka S, Igarashi T, Funae Y. Progesterone oxidation by cytochrome P450 2D isoforms in the brain. Endocrinology, 2001;142:3901-3908.

44. Crewe HK, Lennard MS, Tucker GT, Woods FR, Haddock RE. The effect of selective serotonin reuptake inhibitors on cytochrome P4502D6 (CYP2D6) activity in human liver microsomes. Br J Clin Pharmacol, 1992;34:262-265.

45. Liu ZQ, Cheng ZN, Huang SL, Chen XP, Ou-Yang DS, Jiang CH, Zhou HH. Effect of the CYP2C19 oxidation polymorphism on fluoxetine metabolism in Chinese healthy subjects. Br J Clin Pharmacol, 2001;52:96-99. 
46. Niwa T, Yasumura M, Murayama N, Yamazaki H. Comparison of catalytic properties of cytochromes P450 3A4 and 3A5 by molecular docking simulation. Drug Metab Lett, 2014;8:43-50.

47. Niwa T, Narita K, Okamoto A, Murayama N,
Yamazaki H. Comparison of steroid hormone hydroxylations by and docking to human cytochromes P450 3A4 and 3A5. J Pharm Pharm Sci. 2019;22:332-339. doi: 10.18433/jpps30558. 